Int. J. Dev. Biol. 58: 183-187 (2014)

doi: $10.1387 / \mathrm{ijdb} .130337 \mathrm{hl}$

\title{
Evolving tales of autophagy in early reproductive events
}

\author{
HYUNJUNG J. LIM*,1 and HAENGSEOK SONG*,2 \\ ${ }^{1}$ Department of Biomedical Science \& Technology, Institute of Biomedical Science \& Technology, Konkuk University, \\ Gwangjin-gu and ${ }^{2}$ Department of Biomedical Science, College of Life Science, CHA University, Seoul, Korea
}

\begin{abstract}
Cells learn to thrive under unfavorable conditions by various mechanisms, and autophagy, self-eating, is one such mechanism. Autophagy is always ongoing in cells at a basal level to turn over old proteins, provide building blocks for new proteins, and to dispose of unnecessary byproducts of metabolism, and normally it does not cause deleterious effects on other parts of basic cellular processes. Autophagy is often dubbed a "double-edged sword", as it is a necessary process for many cells, but its exaggeration may lead to cell death. Evidence is accumulating that autophagy is crucially involved in specific aspects of reproduction. Several recent studies have illustrated how the uniqueness of self-eating is manifested in germ cells and embryos. In this review, we attempt to portray where this relatively young field of autophagy research is heading in the context of reproductive biology research.
\end{abstract}

KEY WORDS: autophagy, oocyte, sperm, embryo

\section{Introduction}

Autophagy is an old term describing a cellular pathway by which cellular constituents are brought to lysosomes for degradation (Yang \& Klionsky 2010). Christian de Duve, who was awarded a Nobel Prize for his work on the discovery of lysosomes, first employed the term when he observed intracellular vesicles encircling cytoplasmic materials (Deter \& De Duve 1967; Yang \& Klionsky 2010). This led to the realization that cells degrade their own macromolecules by delivering them to double-membrane vesicles, called autophagosomes, which then proceed to fuse with lysosomes. The fate of the degraded macromolecular constituents does not end in lysosomes; instead, the building blocks are salvaged and recycled. Thus, autophagy is considered a constructive cellular pathway necessary for the maintenance of cell functions. Three types of autophagy have been characterized to date: chaperonemediated autophagy, macroautophagy, and microautophagy (Glick et al., 2010). In this review, we focus on macroautophagy, which involves the initial sequestration of cytoplasmic materials into autophagosomes, as this process has been the focus of interest in physiology and disease research in recent years (Mizushima 2007; Yang \& Klionsky 2010; Boya et al., 2013).

\section{Macroautophagy: a brief overview}

Under a transmission electron microscope (TEM), the initiation of autophagy is distinguished by the formation of a phagophore, a horseshoe-shaped double-membranous structure incompletely encircling a target area within a cell (Klionsky et al., 2012). A phagophore then expands by recruiting more lipid molecules and forms a complete vesicular structure, the autophagosome. When autophagosomes fuse with lysosomes, the lytic pathway ensues with the action of lysosomal enzymes. The inner membrane is also lysed during this process, and thus autophagolysosomes no longer exhibit the typical double-membrane morphology under TEM (Mizushima 2007; Klionsky et al., 2012). Lipid molecules required for the formation of autophagosomes are provided mainly by the endoplasmic reticulum (ER), but other structures, such as the Golgi apparatus, mitochondria, and plasma membrane, also contribute (Tooze \& Yoshimori 2010; Ravikumar et al., 2010).

Many components of the autophagy pathway have names that begin with Atg, indicating autophagy (Boya et al., 2013). Two main ubiquitin-like protein conjugation systems, Atg12 and Atg8, are involved in phagophore expansion and complete formation of autophagosomes (Geng \& Klionsky 2008). Atg12 is covalently conjugated to Atg5 by a two-step process, which involves Atg7 and Atg10. The Atg12-Atg5 complex is then joined by Atg16, and this complex is required during the initial steps of phagophore expansion. Atg8, also called LC3, undergoes a reversible lipidation, rather than a covalent modification, with proteins. LC3-I is the cytosolic form of this protein prior to lipidation, and it is converted by the action

Abbreviations used in this paper: ER, endoplasmic reticulum.

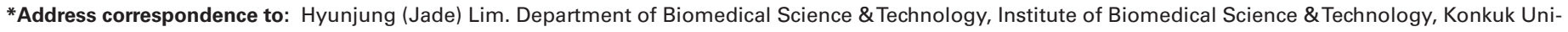

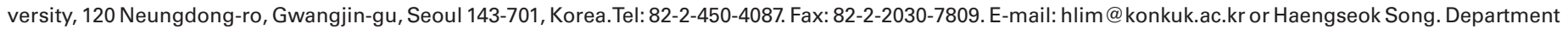
of Biomedical Science, College of Life Science, CHA University, Seoul, Korea. Tel: 82-2-555-5072; E-mail: hssong @cha.ac.kr
} 
of the Atg12-Atg5-Atg16 system to the phosphatidylethanolamine (PE)-conjugated form, LC3-II (Geng \& Klionsky 2008). LC3-II proteins are incorporated into the autophagosomal membrane and remain there until they are cleaved by Atg4 and recycled (Geng \& Klionsky 2008). In mammalian systems, the accumulation of LC3-II is widely used as a monitoring tool of autophagic activation (Klionsky et al., 2012). Atg6, also known as Beclin1, is a subunit of the class III phosphoinositide 3-kinase (PI3K) complex, and it directly interacts with an anti-apoptotic protein, Bcl-2. Beclin1 is involved in induction of autophagy as a component of various $\mathrm{PI}$ KK complexes, and is also recognized as a seminal protein in bridging autophagy and apoptosis at the ER (Chang et al., 2010; Wirawan et al., 2012).

As for inducers of autophagy, "suboptimal environments" of a diverse nature are indicated (Yang \& Klionsky 2010; Boya et al., 2013). From the perspectives of individual cells and organisms, such inducers include, but are not limited to, starvation, lack of growth factors, adverse temperatures, toxic substances, reactive oxygen species (ROS), hypoxia, and crowding. The most wellestablished signaling regulator of autophagy is the mammalian target of rapamycin (mTOR) (Kapahi et al., 2010). mTOR-containing signaling complexes work as integrators of cell growth by regulating protein translation, ER stress, metabolism, autophagy, and other processes (Kapahi et al., 2010). Activation of mTOR signaling is achieved by many factors including amino acids, growth factors, and hormones, whereas its activation is inversely correlated with autophagy which is activated during suboptimal conditions of low nutrients and energy sources (Glick et al., 2010; Kim et al., 2011). Suppression of autophagy by mTOR involves phosphorylation of Atg1(Ulk) complex, a complex known to be required for the induction of autophagy (Kim et al., 2011; Boya et al., 2013). In contrast, AMP activated protein kinase (AMPK) promotes autophagy by phosphorylating Atg1 at a different site (Kim et al., 2011).

\section{Gene deficient mouse models: physiological roles first revealed}

Yeast is the prototypical model organism in autophagy research, as there is high homology between the functional machinery of mammalian autophagy proteins with those of yeast (Boya et al., 2013). The list of mammalian Atg homologs and associated genes of autophagy has been expanding, and the role of each Atg protein at a cellular level has been extensively investigated using mutant yeast and mammalian cell lines (Mizushima 2007). At the whole organism level, several gene-targeted mouse models have been produced and characterized (Yue et al., 2003; Kuma et al., 2004; Komatsu et al., 2005; Marino et al., 2007; Cann et al., 2008; Marino et al., 2010). As crucial upstream components of autophagic activation, Atg5 and Atg7 knockout animals were the first two models that demonstrated essential physiological roles for autophagy in the survival of neonates (Kuma et al., 2004; Komatsu et al., 2005). Atg5 ${ }^{--}$pups failed to thrive after birth and died within several hours of birth (Kuma et al., 2004). Atg $7^{-/-}$mice were generated by conditional targeting of the floxed Atg7 gene with a Zp3-CRE transgenic mouse line, and they exhibit a very similar phenotype to Atg5 $5^{-/-}$mice at birth (Komatsu et al., 2005). These studies showed that autophagy is highly activated within several hours of birth in the muscles of neonates to provide immediate backup energy and nutrients to working muscles during a catastrophic change of environment at birth (Schiaffino et al., 2008). Autophagic activation is observed mainly in the liver and skeletal muscle in neonates, reflecting the fact that autophagy is required to cope with any sudden need for an independent energy source after being severed from placental circulation (Kuma et al., 2004; Komatsu et al., 2005; Schiaffino et al., 2008). Beclin1-deficient embryos exhibit early lethality around $\mathrm{E} 7.5$, and this phenotype is associated with increased cell death (Yue et al., 2003). Studies using Beclin1 ${ }^{-/}$and Atg5 ${ }^{-/}$embryonic stem (ES) cells further showed that these mutant ES cells fail to cavitate during embryoid body morphogenesis (Qu et al., 2007). Thus, a role for autophagy in the clearance of apoptotic cells during cavitation was demonstrated. Other mouse models harboring tissue-specific deletion of Atg genes have been thoroughly described in recent review articles, along with their implications for broader disciplines (Cecconi \& Levine 2008; Hale et al., 2013).

\section{Autophagy in reproduction: from germ cells to implantation}

\section{Death of germ cells in the prenatal ovary}

In mammalian species, mechanisms of germ cell death function to maintain a finite follicular reserve in the ovary (Tam \& Snow 1981). In the mouse ovary, the germ cell number steeply decreases after birth, and a gradual further reduction is noted in prepubertal and adult ovaries when atresia of primordial follicles is ongoing (Tilly 2001; Rodrigues et al., 2009). In recent years, autophagy has been identified as one way of reducing the reserve of primordial follicles in addition to apoptosis in rodents (Lobascio et al., 2007; Escobar et al., 2008; Rodrigues et al., 2009). When fetal mouse oocytes isolated at E15.5 were cultured in vitro, more than half showed signs of apoptosis within 3-4 days in culture (Lobascio et al., 2007). Among these, a subset of oocytes contained membrane-bound cytoplasmic vesicles, indicating that autophagy was also activated. Most of the cultured fetal oocytes showed positive Beclin1 staining (Lobascio et al., 2007). In the mouse ovary, increased autophagy along with acidification of lysosomes are implicated in the reduction of germ cell number after birth (Rodrigues et al., 2009). A study using Atg gene-deficient mouse models presented evidence that the initial pool of primordial germ cells requires full-fledged autophagy for survival. On postnatal day 1, both Beclin $1^{+/}$and $\operatorname{Atg} 7^{-/}$mouse ovaries showed strikingly reduced numbers of germ cells (Gawriluk et al., 2011). These studies collectively indicate that autophagy is involved in the survival of primordial germ cells in the prenatal period and also during the gradual reduction of the primordial follicle pool from birth through to adulthood in mice. The exact molecular mechanisms underlying these observations warrant further investigation.

\section{Stress on the male reproductive system: temperature effect and beyond?}

Whether autophagy is involved in the process of spermatogenesis is unknown. However, temperature has been identified as one factor that modulates autophagy in mammalian male germ cells (Gallardo Bolanos et al., 2012; Zhang et al., 2012). Heat stress causes male germ cell loss in the mouse testes, primarily via apoptosis (Yin et al., 1997). A recent report has shown that heating of mouse testes is accompanied by evidence of autophagic activation, and autophagy seems to be implicated in enhancing the rate of apoptotic germ cell loss (Zhang et al., 2012). Cold 
temperatures are also recognized as an inducer of autophagy in mammalian sperm (Gallardo Bolanos et al., 2012). Ethanol and formaldehyde have been shown to increase autophagy in rat Sertoli cells (Eid et al., 2012; Han et al., 2013). However, the potential roles that autophagy plays in developmental and pathological aspects of spermatogenesis remain to be identified and require further investigation.

\section{Allophagy: breaking down paternally inherited organelles}

Upon activation by the widely identified inducers of autophagy, such as oxidative stress, metabolic starvation, heat, and infection, specific subcellular organelles could succumb to autophagy (Bernales et al., 2007; Kim et al., 2007; Kraft et al., 2008; Klionsky et al., 2012). Terms to describe such selective types of autophagy include ER-phagy, ribophagy, and mitophagy (Klionsky et al., 2012). Studies using Caenorhabditis elegans ( $C$. elegans) revealed that mitophagy, in particular, is operative during fertilization when the paternal genome and mitochondria enter oocytes (Al Rawi et al., 2011; Sato \& Sato 2011). These studies showed that the selective degradation of paternal mitochondria by LC3-dependent autophagy, now termed allophagy, is an essential process for successful fertilization in C. elegans (Al Rawi et al., 2011; Sato \& Sato 2011). In mice, however, autophagy does not seem to participate in the removal of paternal mitochondria (Luo et al., 2013).

\section{Post-fertilization autophagy and embryonic development}

Atg $5^{-/}$or Atg $7^{-/-}$pups do not survive beyond a day after birth, and are thus not available to study the impact of the absence of autophagy in adult reproductive phenotypes (Kuma et al., 2004; Komatsu et al., 2005). Mice carrying the floxed Atg5 gene crossed with Zp3 promoter-drive CRE transgenic mice have been useful in examining the role of autophagy in early embryonic development (Tsukamoto et al., 2008). Tsukamoto and colleagues first showed that autophagy is highly activated in oocytes just after fertilization, from 1- to 4-cell stages of development, by using GFP-LC3 transgenic mice (Tsukamoto et al., 2008). GFP-LC3 transgenic mice are widely used as an in vivo model to visualize autophagy, as this line expresses the GFP-LC3 fusion gene under a ubiquitously active strong promoter (Mizushima et al., 2004). Crossing Atg5 ${ }^{\text {flox/- }} ;$ Zp3-CRE female mice with Atg $5^{+/-}$male mice have never produced pups bearing a complete deletion of Atg5, which indicates that complete deletion of Atg5 during the preimplantation period led to their early demise in utero (Tsukamoto et al., 2008). When

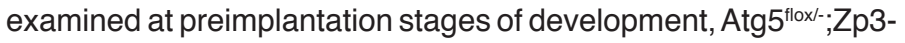
CRE females bred with Atg5 $5^{+-}$males had a subset of embryos that were arrested from the 8-cell stage and never reached the blastocyst stage (Tsukamoto et al., 2008). A copy of the Atg5 gene from $A \operatorname{tg} 5^{+}$sperm is expressed during zygotic gene activation at the 2-cell stage, and was able to partially rescue the phenotype of developmental arrest in Atg5-deficient oocytes after fertilization (Tsukamoto et al., 2008). Autophagy-deficient preimplantation embryos showed a reduction in the rate of overall protein synthesis, and this observation suggested a role for autophagy in recycling building blocks from old proteins for new protein synthesis (Tsukamoto et al., 2008). In porcine embryos, several maternal mRNAs were shown to remain at higher levels when an inhibitor of autophagy, 3-methyladenine (3-MA), was given to 2-cell- or 4-cell-stage embryos (Xu et al., 2012). This result is also indicative of a role for autophagy in breaking down maternal macromolecules after fertilization. Further molecular mechanisms of autophagy governing the turnover of macromolecules in preimplantation embryos are yet to be investigated.

\section{Environmental influence on embryonic autophagy}

In the female reproductive tract, embryos are influenced by the surrounding environment and by the maternal health status. In this regard, elevated levels of glucose and endocannabinoids have been identified as inducers of autophagy in preimplantation embryos (Adastra et al., 2011; Oh et al., 2013). In the mouse uterus, the levels of endocannabinoids oscillate before and after implantation (Schmid et al., 1997), and adequate levels of these lipid mediators are also important for the implantation competence of blastocysts (Wang et al., 2003). When an endocannabinoid analog was given to pregnant mice prior to implantation in order to achieve a higher

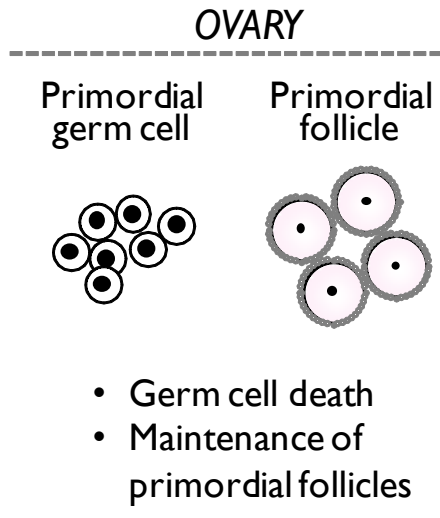

- Germ cell death primordial follicles
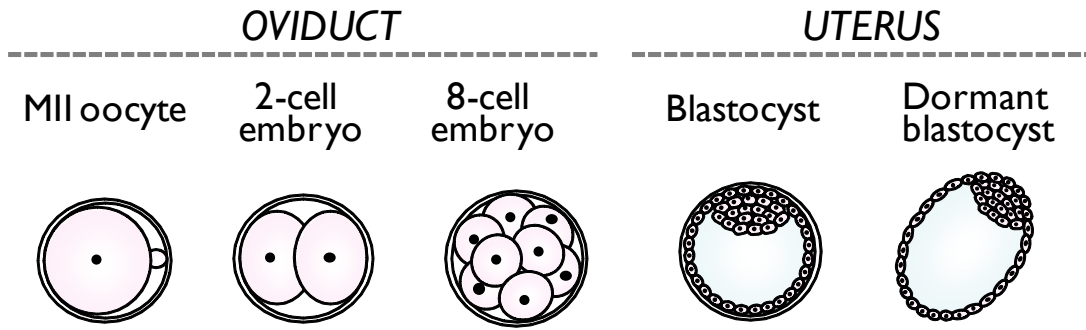

- Degradation of maternal proteins after fertilization

- Response to environmental stress

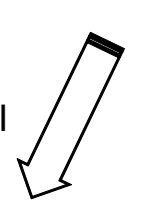

- Cavitation

- Survival during delayed implantation

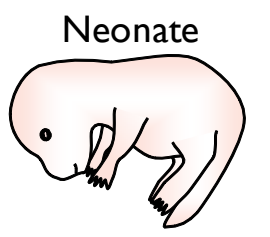

- Survival after birth: nutrient provision

Fig. 1. Summary of potential roles for autophagy in female reproduction in mice. See text for additional information. 
than normal level of endocannabinoids, it induced autophagic activation in blastocysts (Oh et al., 2013). In a streptozotocin-treated diabetes model, oocytes and preimplantation embryos showed increased autophagic responses (Adastra et al., 2011). Although the condition of hyperglycemia produces differential effects on autophagy in various tissues and organs (Fujitani et al., 2009), embryos seem to respond to increased level of glucose in vivo and in vitro by activating autophagy (Adastra et al., 2011). In the cases of both endocannabinoids and glucose, apoptosis is simultaneously upregulated, suggesting a link between these two death pathways (Adastra et al., 2011; Oh et al., 2013). Whether autophagy is further implicated as a response mechanism of mammalian oocytes and preimplantation embryos to other environmental insults still remains to be explored.

\section{When implantation is delayed: survival or death by autophagy}

Blastocysts implant when the uterus reaches the receptive phase under the regulation of ovarian progesterone and estrogen (Dey \& Lim 2006). A small amount of estrogen is critical for activating the blastocyst and preparing the uterus for implantation (Dey \& Lim 2006). When this estrogen is removed from pregnant mice prior to implantation, blastocysts cannot initiate implantation and enter "dormancy" (McLaren 1968). These dormant blastocysts are known to survive in utero for weeks in a free-floating state while the overall metabolic rate is reduced (Van Blerkom et al., 1978; Weitlauf 1974). Delayed implantation in rodents naturally occurs during lactation, whereas in marsupials, mustelids, and several other species, this phenomenon is an obligate process during pregnancy (Renfree \& Shaw 2000). Recently, autophagy has been suggested as a mechanism for survival in dormant blastocysts of experimentally induced delayed implanting mice (Lee et al., 2011). Dormant blastocysts showed heightened levels of autophagy compared to blastocysts reactivated by estrogen for implantation (Lee et al., 2011). As mentioned above, autophagy is considered a survival mechanism during stressful conditions, but its persistent activation could lead to cell death by further activating other death mechanisms (Shintani \& Klionsky 2004). When the period of dormancy was maintained for a longer period of time, embryos became more vulnerable to death when autophagy was inhibited by the injection of 3-MA to the delayed implanting mice. 3-MA-exposed dormant blastocysts also showed higher rate of apoptosis than control embryos (Lee et al., 2011). Thus, the involvement of autophagy in sustained survival of dormant blastocysts was evident, as well as a damaging effect of prolonged autophagy on embryonic survival (Lee et al., 2011). It would be interesting to find out whether autophagic activation also occurs during obligate diapause in other species (Renfree \& Shaw 2000) or in specific gene-targeted mice with a phenotype of deferred implantation (Song et al., 2002).

\section{Conclusion: conjecturing further implications of autophagy in reproduction}

In summarizing the recent literature describing the potential roles for autophagy in various aspects of early pregnancy and development, it has become evident that many questions remain to be addressed. Where any kind of stress is implicated, autophagy may contribute either to the defense or offense in the maintenance of cell survival and homeostasis (Fig. 1). Whether the modulation of autophagy may be beneficial for improving the quality of embryos in assisted reproductive technology is also in the pipeline for further investigation. Autophagy has also been identified as a mechanism utilized during dynamic reconstruction processes occurring within a cell population, such as embryonic cavitation and patterning (Qu et al., 2007; Kawamura et al., 2012). The impact of endocrine disruptors and other environmental toxins on autophagy of germ cells and embryos would also be an exciting topic of future research.

\section{Acknowledgments}

We would like to thank Dr. S. K. Dey for guiding our scientific endeavors ever since our graduate training at the University of Kansas Medical Center. He has achieved unparalleled excellence in reproduction research, and we are very proud to have him as our mentor. What we learned from him has become the cornerstone of our past, present, and future as a team of researcher-teacher. We also would like to thank Ms. S. Bang for the illustration. This work was supported by a National Research Foundation of Korea (NRF) grant funded by the Korea government (MEST) (No.2011-0016513).

\section{References}

ADASTRA KL, CHI MM, RILEY JK, MOLEY KH (2011). A differential autophagic response to hyperglycemia in the developing murine embryo. Reproduction 141: $607-615$.

AL RAWI S, LOUVET-VALLEE S, DJEDDI A, SACHSE M, CULETTO E, HAJJAR C BOYD L, LEGOUIS R, GALY V (2011) Postfertilization autophagy of sperm organelles prevents paternal mitochondrial DNA transmission. Science 334: 1144-1147.

BERNALES S, SCHUCK S, WALTER P (2007) ER-phagy: selective autophagy of the endoplasmic reticulum. Autophagy 3: 285-287.

BOYA P, REGGIORI F, CODOGNO P (2013) Emerging regulation and functions of autophagy. Nat Cell Biol 15: 713-720.

CANN GM, GUIGNABERT C, YING L, DESHPANDE N, BEKKER JM, WANG L, ZHOU B, RABINOVITCH M (2008) Developmental expression of LC3alpha and beta: absence of fibronectin or autophagy phenotype in LC3beta knockout mice. Dev Dyn 237: 187-195.

CECCONI F, LEVINE B (2008) The role of autophagy in mammalian development: cell makeover rather than cell death. Dev Cell 15: 344-357.

CHANG NC, NGUYEN M, GERMAIN M, SHORE GC (2010) Antagonism of Beclin 1-dependent autophagy by $\mathrm{BCL}-2$ at the endoplasmic reticulum requires NAF-1. EMBO J 29: 606-618.

DETER RL, DE DUVE C (1967) Influence of glucagon, an inducer of cellular autophagy, on some physical properties of rat liver lysosomes. J Cell Biol 33: 437-449.

DEY SK \& LIM H (2006) Implantation. In Knobil and Neill's Physiology of Reproduction (Eds J Neill). Elsevier, Philadelphia, pp. 147-188.

EID N, ITO Y, OTSUKI Y (2012) Enhanced mitophagy in Sertoli cells of ethanoltreated rats: morphological evidence and clinical relevance. J Mol Histol43: 71-80.

ESCOBAR ML, ECHEVERRIA OM, ORTIZ R, VAZQUEZ-NIN GH (2008) Combined apoptosis and autophagy, the process that eliminates the oocytes of atretic follicles in immature rats. Apoptosis 13: 1253-1266.

FUJITANI Y, KAWAMORI R, WATADA H (2009) The role of autophagy in pancreatic beta-cell and diabetes. Autophagy 5: 280-282.

GALLARDO BOLANOS JM, MIRO MA, BALAO DA SILVACM, MORILLO RA, PLAZA DM, APARICIO IM, TAPIA JA, ORTEGA FC, PENA FJ (2012) Autophagy and apoptosis have a role in the survival or death of stallion spermatozoa during conservation in refrigeration. PLoS One 7: e30688.

GAWRILUK TR, HALE AN, FLAWS JA, DILLON CP, GREEN DR, RUCKER EB, II (2011) Autophagy is a cell survival program for female germ cells in the murine ovary. Reproduction 141: 759-765.

GENG J, KLIONSKY DJ (2008) The Atg8 and Atg12 ubiquitin-like conjugation systems in macroautophagy. 'Protein modifications: beyond the usual suspects' review series. EMBO Rep 9: 859-864.

GLICK D, BARTH S, MACLEOD KF (2010) Autophagy: cellular and molecular mechanisms. J Pathol 221: 3-12.

HALE AN, LEDBETTER DJ, GAWRILUK TR, RUCKER EB, III (2013) Autophagy: 
Regulation and role in development. Autophagy 9: 951-972.

HAN SP, ZHOU DX, LIN P, QIN Z, AN L, ZHENG LR, LEI L (2013) Formaldehyde exposure induces autophagy in testicular tissues of adult male rats. Environ Toxicol DOI: 10.1002/tox. 21910

KAPAHI P, CHEN D, ROGERS AN, KATEWA SD, LI PW, THOMAS EL, KOCKEL $L$ (2010) With TOR, less is more: a key role for the conserved nutrient-sensing TOR pathway in aging. Cell Metab 11: 453-465.

KAWAMURA N, SUN-WADA GH, AOYAMA M, HARADA A, TAKASUGA S, SASAKI T, WADA Y (2012) Delivery of endosomes to lysosomes via microautophagy in the visceral endoderm of mouse embryos. Nat Commun 3: 1071.

KIM I, RODRIGUEZ-ENRIQUEZ S, LEMASTERS JJ (2007) Selective degradation of mitochondria by mitophagy. Arch Biochem Biophys 462: 245-253.

KIM J, KUNDU M, VIOLLETB, GUAN KL (2011) AMPK and mTOR regulate autophagy through direct phosphorylation of Ulk1. Nat Cell Biol 13: 132-141.

KLIONSKYDJ, ABDALLAFC, ABELIOVICH H, ABRAHAM RT, ACEVEDO-AROZENA A et al., (2012) Guidelines for the use and interpretation of assays for monitoring autophagy. Autophagy 8: 445-544.

KOMATSU M, WAGURI S, UENO T, IWATA J, MURATA S, TANIDA I, EZAKI J, MIZUSHIMA N, OHSUMI Y, UCHIYAMA Y, KOMINAMI E, TANAKA K, CHIBA T (2005) Impairment of starvation-induced and constitutive autophagy in Atg7deficient mice. J Cell Biol 169: 425-434.

KRAFT C, DEPLAZES A, SOHRMANN M, PETER M (2008) Mature ribosomes are selectively degraded upon starvation by an autophagy pathway requiring the Ubp3p/Bre5p ubiquitin protease. Nat Cell Biol 10: 602-610.

KUMA A, HATANO M, MATSUI M, YAMAMOTO A, NAKAYA H, YOSHIMORI T, OHSUMI Y, TOKUHISA T \& MIZUSHIMA N (2004) The role of autophagy during the early neonatal starvation period. Nature 432: 1032-1036.

LEE JE, OH HA, SONG H, JUN JH, ROH CR, XIE H, DEY SK, LIM HJ (2011) Autophagy regulates embryonic survival during delayed implantation. Endocrinology 152: 2067-2075.

LOBASCIO AM, KLINGER FG, SCALDAFERRI ML, FARINI D, DE FELICI M (2007) Analysis of programmed cell death in mouse fetal oocytes. Reproduction 134: 241-252.

LUO SM, GE ZJ, WANG ZW, JIANG ZZ, WANG ZB, OUYANG YC, HOU Y, SCHATTEN H, SUN QY (2013) Unique insights into maternal mitochondrial inheritance in mice. Proc Natl Acad Sci USA 110: 13038-13043.

MARINO G, FERNANDEZ AF, CABRERA S, LUNDBERG YW, CABANILLAS R, RODRIGUEZ F, SALVADOR-MONTOLIU N, VEGA JA, GERMANA A, FUEYO A, FREIJE JM, LOPEZ-OTIN C (2010) Autophagy is essential for mouse sense of balance. J Clin Invest 120: 2331-2344.

MARINO G, SALVADOR-MONTOLIU N, FUEYO A, KNECHT E, MIZUSHIMA N, LOPEZ-OTINC (2007) Tissue-specific autophagy alterations and increased tumorigenesis in mice deficient in Atg4C/autophagin-3. J Biol Chem 282: 18573-18583.

MCLAREN A (1968) A study of balstocysts during delay and subsequent implantation in lactating mice. $J$ Endocrinol 42: 453-463.

MIZUSHIMA N (2007) Autophagy: process and function. Genes Dev 21: 2861-2873.

MIZUSHIMAN, YAMAMOTO A, MATSUI M, YOSHIMORIT, OHSUMI Y (2004) In vivO analysis of autophagy in response to nutrient starvation using transgenic mice expressing a fluorescent autophagosome marker. Mol Biol Cell 15: 1101-1111.

OH HA, KWON S, CHOI S, SHIN H, YOON KH, KIM WJ, LIM HJ (2013) Uncovering a role for endocannabinoid signaling in autophagy in preimplantation mouse embryos. Mol Hum Reprod 19: 93-101.

QU X, ZOU Z, SUN Q, LUBY-PHELPS K, CHENG P, HOGAN RN, GILPIN C, LEVINE $B$ (2007) Autophagy gene-dependent clearance of apoptotic cells during embryonic development. Cell 128: 931-946.
RAVIKUMAR B, MOREAU K, JAHREISS L, PURI C, RUBINSZTEIN DC (2010) Plasma membrane contributes to the formation of pre-autophagosomal structures. Nat Cell Biol 12: 747-757.

RENFREE MB, SHAW G (2000) Diapause. Annu Rev Physiol 62: 353-375.

RODRIGUES P, LIMBACK D, MCGINNIS LK, PLANCHA CE, ALBERTINI DF (2009) Multiple mechanisms of germ cell loss in the perinatal mouse ovary. Reproduction 137: 709-720.

SATOM, SATOK (2011) Degradation of paternal mitochondria by fertilization-triggered autophagy in C. elegans embryos. Science 334: 1141-1144.

SCHIAFFINO S, MAMMUCARI C, SANDRI M (2008) The role of autophagy in neonatal tissues: just a response to amino acid starvation? Autophagy 4: 727-730.

SCHMID PC, PARIA BC, KREBSBACH RJ, SCHMID HH, DEY SK (1997) Changes in anandamide levels in mouse uterus are associated with uterine receptivity for embryo implantation. Proc Natl Acad Sci USA 94: 4188-4192.

SHINTANI T, KLIONSKY DJ (2004) Autophagy in health and disease: a double-edged sword. Science 306: 990-995.

SONG H, LIM H, PARIA BC, MATSUMOTO H, SWIFT LL, MORROW J, BONVENTRE JV, DEY SK (2002) Cytosolic phospholipase A2alpha is crucial [correction of A2alpha deficiency is crucial] for 'on-time' embryo implantation that directs subsequent development. Development 129: 2879-2889.

TAM PP, SNOW MH (1981) Proliferation and migration of primordial germ cells during compensatory growth in mouse embryos. J Embryol Exp Morphol 64: 133-147.

TILLY JL (2001) Commuting the death sentence: how oocytes strive to survive. Nat Rev Mol Cell Biol 2: 838-848.

TOOZE SA, YOSHIMORI T (2010) The origin of the autophagosomal membrane. Nat Cell Biol 12: 831-835.

TSUKAMOTO S, KUMA A, MURAKAMI M, KISHI C, YAMAMOTO A, MIZUSHIMA N (2008) Autophagy is essential for preimplantation development of mouse embryos. Science 321: 117-120.

VAN BLERKOM J, CHAVEZ DJ, BELL H (1978) Molecular and cellular aspects of facultative delayed implantation in the mouse. Ciba Found Symp 141-172.

WANG H, MATSUMOTO H, GUO Y, PARIA BC, ROBERTS RL, DEY SK (2003) Differential $G$ protein-coupled cannabinoid receptor signaling by anandamide directs blastocyst activation for implantation. Proc Natl Acad Sci USA 100: 14914-14919.

WEITLAUF HM (1974) Metabolic changes in the blastocysts of mice and rats during delayed implantation. J Reprod Fertil 39: 213-224.

WIRAWAN E, LIPPENS S, VANDEN BERGHE T, ROMAGNOLI A, FIMIA GM, PIACENTINI M, VANDENABEELE P (2012) Beclin1: a role in membrane dynamics and beyond. Autophagy 8: 6-17.

XU YN, SHEN XH, LEE SE, KWON JS, KIM DJ, HEO YT, CUI XS, KIM NH (2012) Autophagy influences maternal mRNA degradation and apoptosis in porcine parthenotes developing in vitro. J Reprod Dev 58: 576-584.

YANG Z \& KLIONSKY DJ (2010) Eaten alive: a history of macroautophagy. Nat Cell Biol 12: 814-822.

YIN Y, HAWKINS KL, DEWOLF WC, MORGENTALER A (1997) Heat stress causes testicular germ cell apoptosis in adult mice. J Androl 18: 159-165.

YUE Z, JIN S, YANG C, LEVINE AJ, HEINTZ N (2003) Beclin 1, an autophagy gene essential for early embryonic development, is a haploinsufficient tumor suppressor. Proc Natl Acad Sci USA 100: 15077-15082.

ZHANG M, JIANG M, BI Y, ZHU H, ZHOU Z, SHA J (2012) Autophagy and apoptosis act as partners to induce germ cell death after heat stress in mice. PLoS One 7: e41412. 


\section{Further Related Reading, published previously in the Int. J. Dev. Biol.}

Metabolism throughout follicle and oocyte development in mammals

Esther Collado-Fernandez, Helen M. Picton and Rémi Dumollard

Int. J. Dev. Biol. (2012) 56: 799-808

http://dx.doi.org/10.1387/ijdb.120140ec

The role of Akt signalling in the mammalian ovary

Sandra Cecconi, Annunziata Mauro, Valerio Cellini and Felice Patacchiola

Int. J. Dev. Biol. (2012) 56: 809-817

http://dx.doi.org/10.1387/ijdb.120146sc

Involvement of adipokines, AMPK, PI3K and the PPAR signaling pathways in ovarian follicle development and cancer

Joëlle Dupont, Maxime Reverchon, Lucie Cloix, Pascal Froment and Christelle Ramé

Int. J. Dev. Biol. (2012) 56: 959-967

http://dx.doi.org/10.1387/ijdb.120134jd

Stage-specific regulation of programmed cell death during oogenesis of the medfly Ceratitis capitata (Diptera, Tephritidae)

Athanassios D. Velentzas, Ioannis P. Nezis, Dimitrios J. Stravopodis, Issidora S. Papassideri and Lukas H. Margaritis

Int. J. Dev. Biol. (2007) 51: 57-66

http://dx.doi.org/10.1387/ijdb.062164av

\section{Reproductive ageing and the menopause}

C A Finn

Int. J. Dev. Biol. (2001) 45: 613-617

http://dx.doi.org/10.1387/ijdb.11417906

5 yr ISI Impact Factor $(2011)=2.959$
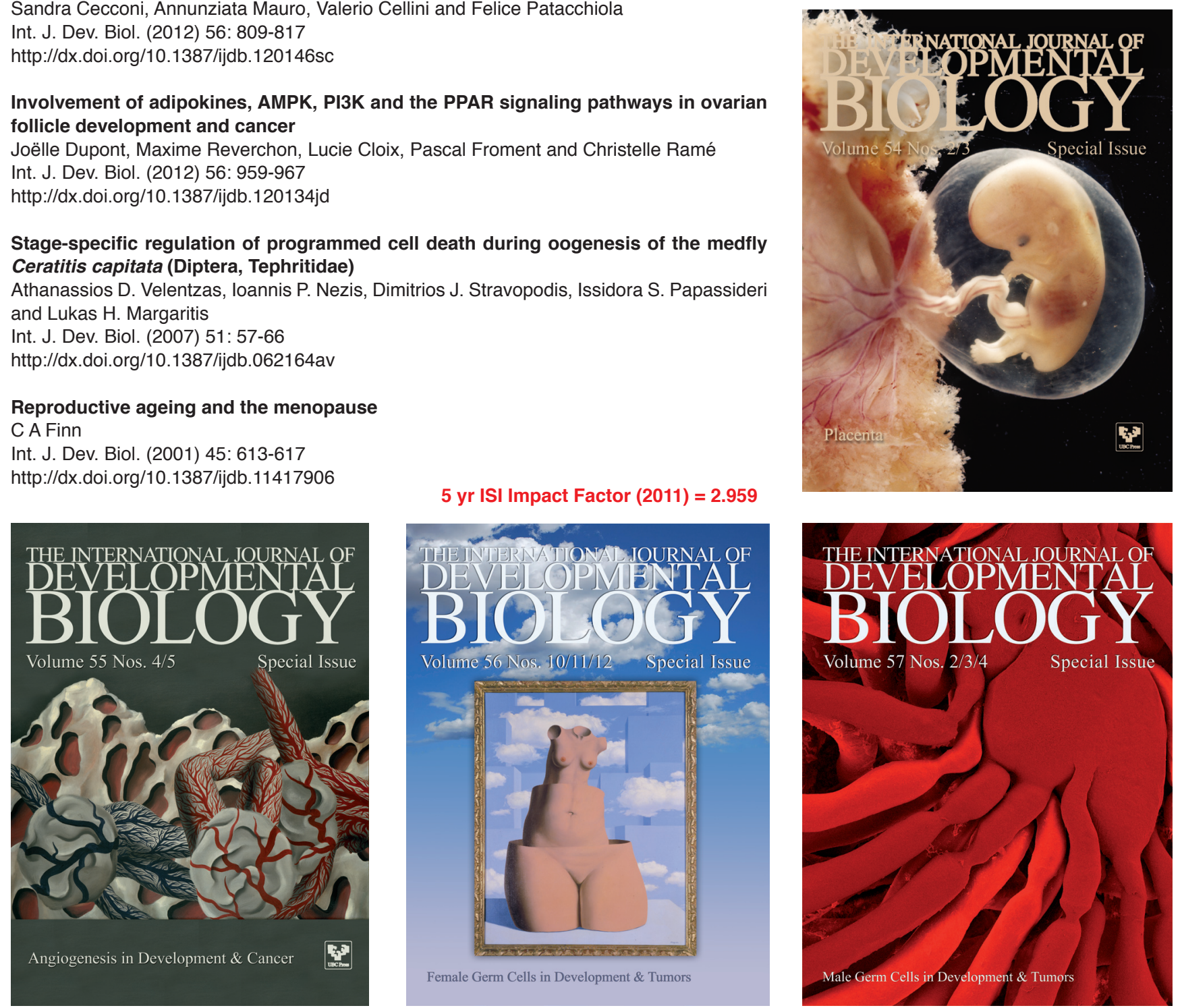